\title{
A construção de casos sobre a midiatização e a circulação como objetos de pesquisa: das lógicas às analogias para investigar a explosão das defasagens
}

Jairo Ferreira

Resumo: Neste artigo, propomos uma perspectiva para a construção de casos de pesquisa sobre midiatização e circulação. Partindo dos esquemas de Verón, nossa proposição acentua a explosão de defasagens entre lógicas de produção e de reconhecimento como fenômeno central nos processos de midiatização. A problemática do método está direcionada para esse ambiente em diferenciação. O fio sugerido para investigar objetos em expansão, a saber, meios, lógicas de produção e recepção, usos e práticas, circuitos e ambientes, novas narrativas e percursos, etc., é dado pelos indícios, pelas inferências e relações analógicas, centrais na constituição de casos de investigação desenhados pelo argumento abdutivo.

Palavras-chave: analogia; midiatização; circulação; epistemologia; metodologia.

Abstract: The case construction on mediatization and circulation as research objects: from the logics to the analogies in order to investigate the explosion of lags - In this paper, we propose a perspective for the construction of case studies on mediatization and circulation. Starting from Verón's schemes, our proposition highlights the explosion of lags between logical production and recognition as a central phenomenon of mediatization processes. The set of problems concerning the method is directed to this environment in differentiation. The suggested axis to investigate objects in expansion, as media, logics of production and reception, uses and practices, circuits and environments, new narratives and routes, etc., is given by the evidences, the inferences and the analogical relationships, which are central in the constitution of case studies developed by abductive argument.

Keywords: analogy; mediatization; circulation; epistemology; methodology. 


\section{O objeto: investigação dos processos midiáticos na perspectiva da midiatização e circulação}

Entendemos a midiatização como o conjunto (feixe) de relações entre (a) acessos, usos, práticas e poderes dos meios, (b) processos comunicacional-midiáticos e (c) construções simbólico-sociais, incluindo a construção de valores em jogo em qualquer processo de interação e comunicação (FERREIRA, 2006). É no âmbito dos processos comunicacional-midiáticos (b) que situamos o problema da circulação, mas esse foco não desfaz, na reflexão, a necessária remissão ao lugar dos meios e das construções simbólicas que se articulam com esses processos acentuados.

A circulação como objeto de pesquisa é, no âmbito da vertente latino-americana inaugurada por Eliseu Verón, um dos eixos centrais nas investigações sobre a midiatização (que entendemos como um ângulo epistemológico específico de investigação dos processos midiáticos). Investigar nessa perspectiva situa essa linhagem de pesquisa entre as epistemologias da comunicação, em diálogo com percursos históricos na área (estudos de produção; de recepção; de produto), os quais procuramos integrar, negar e inovar, superando-os e consolidando novos aportes teóricos e metodológicos.

Essa perspectiva não é a mesma em voga entre os nórdicos, para os quais é visível uma distância em relação ao problema comunicacional, na medida em que acentuam a dimensão social, política e cultural relacionada aos processos midiáticos (BRAGA, 2015). Autores como Hepp e Hjarvard (2015), Strömbäck (2008), entre outros, não situam no âmago do conceito de midiatização que sugerem, em construção, o problema da circulação. Por que não?

A nossa inferência é de que alguns desses autores não tomam a questão comunicacional-midiática como central, conforme as linhagens de pesquisa em comunicação (a relação da produção com o problema da recepção, dos usos, do consumo). O foco são as relações entre processos midiáticos e processos sociossimbólicos sem a mediação de questões e problemas inaugurados pela comunicação midiática (cuja lógica remete à tríade produção, recepção e circulação). Miège (2006) e Peraya (1999) são os mais próximos dessas reflexões desenvolvidas nas correntes sul-americanas, cujos polos estão em grupos de pesquisa na Universidade Nacional de Rosário, na Universidade de Buenos Aires e no grupo a que pertencemos.

Neste artigo, nosso objetivo é, partindo da herança de Verón, fazer questionamentos e proposições às investigações sobre a circulação. Nesse sentido, (a) apresentamos resumidamente a proposta deVerón para a análise da circulação. Depois, (b) desenvolvemos proposições (sobre a expansão e complexificação do conceito de defasagens; novos modelos de circuito-ambiente [BRAGA, 2015; GOMES, 2011] comunicacional a partir dos meios em redes digitais; e, sinteticamente, sobre o que é comunicação nesse processo). A seção posterior (c) apresenta uma proposta de método - as analogias - para a constituição 
de casos de investigação sobre a circulação, considerando-se a explosão das defasagens, em novos circuitos e ambientes midiáticos, que caracterizamos como hipercomplexos a partir das redes digitais.

\section{Das gramáticas às figuras}

A circulação como objeto é discutida por Verón, fundador dessa linhagem de pesquisa na América Latina, no âmbito de um modelo de comunicação em que produtores e receptores estão em posições diferenciadas em termos discursivos, conforme o modelo canônico da comunicação.

Esquematicamente, a proposta de Verón para a investigação da circulação parte do discursivo. Nesse nível, a questão foi por ele colocada como relações entre gramáticas de produção e gramáticas de reconhecimento. Ele articula o discursivo com o processo comunicacional sociomidiático. Os seus estudos acentuam, como afirmamos, processos que caracterizamos como defasagens entre essas duas instâncias, considerando-se espaços específicos, delimitados por técnicas e tecnologias transformadas em meios. O esquema é assim formulado por Boutad e Verón (2007):

Se partimos, no curso de uma uma investigação, de um conjunto de discursos, tomado como "corpus" (D), este pode ser encarado como uma configuração de superfícies discursivas constituídas por operações que reenviam a uma gramática de produção (GP), a qual se explica por sua vez por um conjunto de condições de produção (CP). Se a constituição de uma GP pode ser considerada como um trabalho descritivo, de identificação de invariantes operatórias, identificadas no conjunto D de superfícies discursivas, a GP, uma vez caracterizada, permite definir D como uma classe de discurso: este é o caso de uma GP como contrato de leitura de um meio de imprensa, por exemplo. O que interessa aqui é sublinhar o fato de que se a análise nos permite articular a classe $\mathrm{D}$ de discurso a uma gramática de produção dada, as propriedades de D assim descritas não nos autorizam a inferir os "efeitos" desta classe de discurso na recepção; a classe D está submetida, na recepção, a uma pluralidade de "leituras" e de interpretações, que designamos como Gramáticas de Reconhecimento (GR) de D, e que reenviam por sua vez a condições de reconhecimento (CR) determinadas. Temos aí uma prova capital sobre a não linearidade da comunicação, que resulta do estudo empírico da circulação discursiva (BOUTAUD; VERON, 2007, p.3).

Outro modelo, muito utilizado em pesquisas da linha de pesquisa Midiatização e Processos Sociais, é o que chamamos de sociomidiático, pois abrange a localização de atores e instituições, além dos meios. Nesse modelo, Verón fala em meios. Ou seja, as mútuas remissões nas interações e relações entre atores, instituições e meios diagramam, em nossa perspectiva, as interações comunicacionais em posições de produção e de recepção midiática. Essa remissão aos atores e instituições indica o caminho para fazer 
inferências sobre a incidência da midiatização nos processos sociais. Esses abrangem não apenas as interações entre produção e recepção que ocorrem dentro dos processos midiáticos, mas também aqueles processos sociais que são acionados pelos processos midiáticos e ocorrem fora desses processos como interações sociais.

Qual o método para a investigação empírica da circulação em Verón? Essas investigações são situadas pelo autor explicitamente como duas pesquisas sobre a circulação: Les spectacles scientifiques télévisés? (1985); Ethnographie de l'exposition: I'espace, le corps et le sens (1989). O que é transversal nos dois estudos? O uso de figuras, diagramas e ícones na construção dos objetos de investigação e, depois, nas inferências sobre os processos analisados. Nesse sentido, nas duas pesquisas, pode-se observar a construção icônica dos objetos. Mesmo que assim não sejam nominadas e conceituadas, Verón, nos sucessivos esquemas de análise dos processos midiáticos que estuda como casos, utiliza metáforas como referência central do que chama de gramáticas de produção e reconhecimento.

Isso é coerente com uma formulação no primeiro dos dois estudos. No primeiro desses estudos (FOUQUIER; VERÓN, 1985), o conceito de figuras (BARTHES,1981) é o que direciona metodologicamente a análise dos processos de produção. No segundo estudo, a análise ganha uma configuração peirceana (em que símbolo, ícone e índice são categorias metodológicas). Optamos por esse retorno às figuras. Por quê? Argumentamos a seguir.

\section{As defasagens}

O foco na defasagem é uma escolha nossa, feita a partir de inferências em torno dos esquemas de Verón. Já em sua formulação, a proposição está também evidenciada:

Como construir estes coletivos? Esta é a questão crucial dos estudos em recepção, questão tão mais complicada quando os meios mesmos estão produzindo coletivos (públicos, audiências, leitores), obtidos por procedimentos estatísticos cada vez mais sofisticados, no marco de seus esforços permanentes de articular a oferta e a demanda, reduzindo, tanto quanto possam, a defasagem estrutural crescente entre produção e recepção (BOUTAUD; VERÓN, 2007, p. 4).

Há quem situe essa problemática como uma virada epistemológica em Verón. É o que formula Olivera:

[...] (a) por um lado, a midiatização [é vista em Verón] como condição de possibilidade de emergência de um pensamento ternário sobre a linguagem e sentido, e (b) inversamente, o conceito de decalagem (defasagem, desencaixe, defasagem) entre produção e reconhecimento - núcleo constitutivo do sentido - opera como a superfície argumentativa da emergência do conceito veroniano de midiatização (OLIVERA, 2015, p. 109). 
O pressuposto é que a midiatização revela as diferenciações dos processos de significação. Nesse sentido, a semiose é a infraestrutura do processo de significação. A espécie se diferencia de outras espécies animais pela riqueza em contrapor-se à diferenciação e defasagem por meio de uma parafernália superestrutural - constituindo uma cultura específica. A superestrutura analisada por Verón é a interação discursiva conforme o modelo canônico, em que atores, instituições midiatizadas e instituições midiáticas estão em interação. Entretanto, há outras superestruturas além do discurso (normas e valores, em especial). Entre a semiose e o discurso, há a linguagem (e nisso, os humanos são próximos de outras espécies animais), os códigos, a língua (e nisso começamos a nos diferenciar, pela interposição da lógica), a técnica e a tecnologia.

A questão aqui é como essa superestrutura regula, resolve, problematiza, soluciona, etc. questões da infraestrutura, a semiose. A dificuldade aumenta, pois na gênese históricosocial a semiose é um processo de diferenciação, em termos de significação individual e social. Sendo o processo de significação biológico, psicológico e social (PIAGET, 1973), a tensão se coloca entre a potência da diferenciação (bio-psico-sócio-histórica) e a capacidade social de realizar as trocas de forma cooperativa, colaborativa ou ritualística e hierárquica.

Numa perspectiva da semiótica peirceana, a significação social pode ser compreendida como um processo de diferenciação de operações mobilizando ícones, índices e símbolos sociais. Esse processo de significação, entretanto, não existe por si. Ele passa pelos sistemas de inteligibilidade (cognição, percepções, intuições etc.) da espécie, que constrói normas, valores e discursos que passam a regular a diferenciação. Portanto, soma-se à diferenciação genética uma outra, construída socialmente, não só pelo gesto comunicacional, mas também pela coerção.

Em termos comunicacionais, essa perspectiva converge com as proposições de Elizabeth Walther-Bense (ibidem), que situam a problemática da significação na esfera da semiose. Conforme Walther-Bense (2000), toda interação comunicacional é uma relação entre dois repertórios de signos, dos emissores e de receptores e/ou de interlocutores, como preferimos chamá-los em termos das relações em redes digitais. Esse repertório (ibidem) não é homogêneo. Na interação, há uma zona compartilhada de repertórios, a partir da qual se estabelece uma zona comum, que é tensionada pela zona de diferenças. O problema colocado pela autora é bem situado para nossa reflexão. Os repertórios não contêm signos homogêneos. Ela não fala de conteúdos. Fala de operações. Trata de afirmar que os repertórios são operações semióticas que os interlocutores, nas posições de emissores, receptores ou de receptores produtivos, acionam quando determinado objeto está em jogo.

As defasagens acentuadas por Verón seriam, nessa perspectiva semiótica, manifestações de um processo que eclode, que se revela na superfície discursiva, colocando em xeque discursos sócio-históricos, incluindo seus antecedentes, as linguagens e os códigos linguísticos. A língua e os discursos, pelo contrário, seriam construções 
histórico-sociais pós-ritualísticas, incorporando lógicas de rituais, através das quais a espécie tenta regular o processo de diferenciação, decalagens e defasagens nas interações sociais. Elas não se constituem nos únicos meios sociais de regulação. Os valores sociais se constituem em outras formas de restabelecimento de um vínculo sempre erodido pela diferenciação semiótica que se manifesta nas esferas do biológico, psicológico, antropológico, sociológico e comunicacional. E, finalmente, a técnica e a tecnologia também se constituem em tentativas de regulação, através do contato que produzem entre os diferenciados.

Ao contrário de outras espécies animais em que a diferenciação se regula por meio de rituais, relações diretas de poder ou violência, a espécie humana vive a tensão entre os rituais e o poder, a necessidade lógica, a busca da cooperação, da transcendência e, até mesmo, da comunicação entre os diferentes, tentando romper com a violência como paradigma de resolução. Nesse sentido, entendemos que a tensão entre defasagens e ternários se manifesta na midiatização - fragmentação e defasagens estão em permanente tensão com as tentativas (a comunicação tentativa de Braga), valendo-se para isso até mesmo de objetos sociais construídos: o vínculo, o amor, a norma, a pólis etc. e dos meios técnicos e tecnológicos.

\section{Matrizes complexas em redes digitais}

As questões podem ser agora colocadas: quais são as condições comunicacionais que propiciam a eclosão das defasagens, derivadas das diferenciações? Em que contexto específico as diferenciações potenciais se realizam? Por que a investigação deve superar a busca de lógicas, de normas, de códigos, como aspecto central desse processo? Como situar a analogia como método de análise da diferenciação e das defasagens nas interações? Em que medida a análise por analogia oferece novas respostas para a problemática do ternário?

Retomamos aqui a proposição acima: a semiose é a infraestrutura do processo de significação. A superestrutura é composta por valores, normas sociais e discursos (que mobilizam linguagens, a língua e os códigos). Entre esses dois processos, é central a forma histórico-social que assume a comunicação sociomidiática. As análises da circulação são realizadas por Verón conforme uma matriz complexa simples, descrita no item 2, acima:

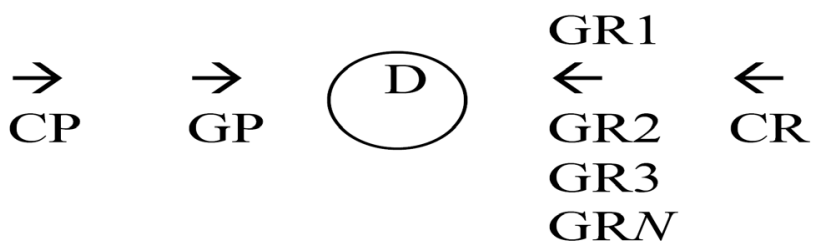

Fig.1. A circulação discursivo-midiática (VERÓN, 2007, p. 3). 
Numa lógica matricial, a proposta de Verón é o agrupamento de indivíduos receptores (1 a " $\mathrm{n}$ ") em " $\mathrm{m}$ " gramáticas de reconhecimento correspondentes a uma ou mais gramáticas de produção.

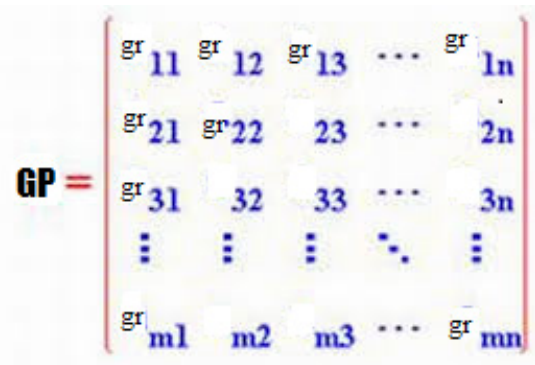

Fig.2. Matriz de processos midiáticos em que poucos meios detém o monopólio discursivo

A explosão das defasagens, que são potencialmente alimentadas pela diferenciação dos processos de significação, só se realiza num cenário em que os meios e os processos midiáticos - as redes digitais - possibilitam que cada um dos indivíduos-atores se coloque como produtor de GP, o que nos permite inferir a possibilidade de que um corpus possa ser analisado como $M \times N$ gramáticas de produção, em que as instituições midiáticas constituem uma das matrizes possíveis, não mais determinante, como sugeriu o conceito de indústria cultural.

Nesse cenário, a disrupção passaria a agenciar os processos tentativos de inteligibilidade e as tentativas de regulação das interações. O desequilíbrio passaria a dominar os processos, requisitando, por isso mesmo, os algoritmos como sistemas de regulação.

Nesse contexto, há proposições concorrentes: a) as defasagens passam a se constituir em uma questão antológica, na medida em que as epistemes não produzem os fechamentos lógicos, racionais ou simbólicos sugeridos pela modernidade e nem as regulações técnicas e tecnológicas sugeridas como ideologia oferecem resolução para o problema da inteligibilidade; b) propostas que reconhecem que as defasagens ou decalagens têm como resultados sócio-históricos, em novos contextos dos processos midiáticos, a explosão e fragmentação de sentidos, mas, por outro lado, vêm propiciando a constituição de novos cenários simbólicos (ternários), mais complexos do que os até então configurados pela experiência da espécie.

\section{As analogias}

O analógico pode ser, pelo prefixo an, negação, oposição, separação, diminuição, falta ou reforço de lógica. Essa multiplicidade semântica dá ao termo um lugar especial na solução que buscamos para o método de análise de processos não lineares, em que sentimentos e experiência, existência e forma se articulam na analítica e crítica sobre 
os processos midiáticos. Essa sugestão não nega a existência de lógicas específicas nos processos midiáticos, mas informa que a investigação, ao deparar-se com diversas lógicas específicas, em defasagens diversas, deve transitar para um espaço reflexivo mais fluido, no qual a negação das lógicas, suas oposições, separações, redução de força, falta, ou, mesmo reforço, são concomitantes, conforme o caso em investigação.

Já na análise da circulação conforme seu modelo, Verón (2001) identificou a problemática da circulação como espaço de incerteza e indeterminação. Essa identificação é central em sua crítica aos estudos em comunicação que têm como referência a possibilidade de se estabelecer uma relação entre mapa sociodemográfico e sentido, nas interações discursivas. Essa formulação já tinha também sido inferida por nós (FERREIRA, 2002), na análise das interações em listas de discussões. Isso demanda uma pesquisa empírica que supere a análise sociodemográfica de condutas, conforme o modelo matricial anterior, em que a existência de poucos meios determinantes (monopólio) reduzem a complexidade.

Esse é o ponto convergente com Verón.

O divergente? Os circuitos-ambientes de redes digitais em análises são exponenciais, multiplicados por " $\mathrm{m}$ " $\mathrm{x}$ " $\mathrm{n}$ " produtores, conforme atores, instituições midiatizadas e instituições midiatizadas em interação, potenciais e realizadas. Num ambiente com tal complexidade, a incerteza e a indeterminação passariam a configurar a característica do ambiente interacional. O impasse da pesquisa passa a ocorrer em dois níveis: a) do método de construção do caso, considerando-se que agora o pesquisador enfrenta um ambiente de complexidade exponencial. O que observar?; b) metodológico, relativo ao processo de coleta, organização e análise dos dados relativo ao caso construído. Por um lado, temos a proposta de análise a partir de métricas (Big Data), como forma de dar conta de matrizes hipercomplexas. Por outro, a proposição de análise que sugere a construção de casos, recortados do ambiente hipercomplexo, que é composto por " $\mathrm{m}$ x n" casos (casos relativos a instituições midiáticas, instituições midiatizadas e atores em interação na condição de produtores e receptores). O pressuposto ontológico é de que, numa sociedade complexa e diferenciada, a analogia é o caminho de investigação porque é impossível uma análise a partir do princípio de identidade (em que todos os objetos materiais seriam os mesmos), que é requisitado no estabelecimento de relações lógico-racionais.

Atualizando nossa formulação: na análise das interações comunicacionais em rede é impossível antecipar a especificidade dos circuitos, dos ambientes de interação, dos novos paradigmas de interação que emergem, das narrativas reconstruídas, dos pontos de bifurcação, a sucessão de bifurcações, as defasagens decorrentes, os trajetos e vias dominantes, as subordinadas que as alimentam etc. Por isso, a importância das operações analógicas.

Importante aqui a sugestão de Pignatari (2004) sobre o ícone como primeirização do terceiro. Adicionamos que se trata também de primeirização do segundo (o objeto). Há uma dupla suspensão. Primeiro, o trabalho de constituição de casos requer a suspensão 
dos conceitos, hipóteses genéricas, relações teóricas instaladas. Diz ele: "essa ideia do ícone como quase-objeto e que pode, inclusive, em sua manifestação mais genuína, ser uma representação analógica que cria ou suscita o objeto representado - uma fórmula algébrica, um diagrama de Venn" (ibidem, p. 59).

Nessa suspensão, é fundamental o artesanato que reúne indícios e inferências e relações entre inferências. Suspende-se, portanto, também o objeto. Ele só existe (real) através dos indícios. Este trabalho artesanal situa a problemática teórico-investigativa no plano dos ícones, imagens, diagramas, metáforas, hipoícones de ligação (ibidem). Nesse sentido, uma teoria nova ou quase nova é proposta através de vários diagramas relacionais: "ora, o diagrama, embora apresente traços simbolóides, bem como traços que o aproximam da natureza dos índices, é, antes de mais nada, um ícone das formas de relações na constituição de seu objeto, sendo fácil de ver a sua adequação à inferência necessária" (ibidem, p. 59).

\section{Analogia e argumento}

Nessa perspectiva, buscamos em Peirce (1958) proposições articuladoras entre analogia e inferência abdutiva. A analogia é fartamente pensada como um tipo de raciocínio, ganhando, em sua obra, várias tonalidades. Sistematizamos essas proposições de forma lógica (sem nos preocuparmos com o processo genético e construtivo).

Também em Peirce, a analogia é vizinha da semelhança, porém marcada pela incompletude em relação ao objeto a que se refere (quase objeto). É uma relação entre o diagrama (o primeiro) e o fato observado, sendo um raciocínio necessário à criação do signo semelhante ao objeto do discurso, por meio de esquemas. Aqui, a analogia é uma operação solidária à abdução, sendo operação requisitada à inferência do primeiro dos signos (o ícone), anterior ao índice e ao símbolo. O diagrama não é semelhante sensualmente ao objeto que representa, mas sim análogo, uma forma, que, sucessivamente, se aproxima do conceito. Portanto, é um pré-conceito. A analogia servirá não só para definir a identidade do ícone, mas também, por diferença, definir o que, no índice e no símbolo, opera como transformação.

O lugar que ocupa a analogia, de relação entre o objeto do discurso e o diagrama construído sobre ele, vai localizar o raciocínio por analogia como parte da construção de hipóteses, num esforço de diferenciação entre o que são hipóteses e analogias. Nessa diferenciação, identificamos a analogia como interface entre os três argumentos, sendo requisitada para que se realizem (a indução, dedução e abdução). Na dedução, observar e experimentar analogias entre o diagrama construído e o objeto ampliado do raciocínio possibilita descobrir novas relações, invisíveis no diagrama anterior. Na indução, o raciocínio por analogia permite trabalhar metodologicamente com uma classe de amostragem pequena, que propicia inferências sobre uma população, as quais vão sendo sucessivamente observadas e experimentadas. 


\section{O lugar da analogia na construção do caso de investigação}

Como já foi indicado acima, a analogia é operação que se insere na construção dos argumentos abdutivo, dedutivo e indutivo. O caso aqui sugerido é uma inferência do método. Não se confunde com o caso abordado como metodologia, conforme os manuais de vulgarização nas ciências sociais. Nesse sentido, o caso como inferência, na perspectiva do método, é o primeiro argumento a ser construído na pesquisa empírica. Esquematicamente, conforme Ferreira (2012):

\begin{tabular}{|c|c|c|c|}
\hline & & & Inferência? \\
\hline Dedução & $\begin{array}{l}\text { Caso: relações entre inferências } \\
\text { e inferências conforme indicios } \\
\text { relevantes e materialidades } \\
\text { ohservadas T́cones. hipoicones, } \\
\text { diagramas, figuras. Quasc } \\
\text { conceitos e quase objetos no } \\
\text { contexto de circuitos- } \\
\text { ambientes Atores. institniçnes } \\
\text { midiatizadas midiáticas cm } \\
\text { interação, situados como } \\
\text { produtores e/ou receptores. }\end{array}$ & $\begin{array}{l}\text { Análise das interações no } \\
\text { âmbito de circuitos e ambientes } \\
\text { desenhados. }\end{array}$ & $\begin{array}{l}\text { Ampliação das inferências, } \\
\text { conforme proposiçoes. } \\
\text { ldentificação de usos, práticas, } \\
\text { tentativas de apropriaçñes } \\
\text { Disposiçõcs discursivas. } \\
\text { Dissipaçōes decorrentes das } \\
\text { defasagens. Novas questões. }\end{array}$ \\
\hline Indução & $\begin{array}{l}\text { Caso: relações entre inferências } \\
\text { e inferências conforme indicios } \\
\text { relevantes e materialidades } \\
\text { observadas. Ícones, hipoicones. } \\
\text { diagramas, figuras. Quase } \\
\text { conceitos e quase objetos no } \\
\text { contexto de circuitos- } \\
\text { ambientes. Atores. instituições } \\
\text { midiatizadas e midiáticas em } \\
\text { interação, situados como } \\
\text { produtores e/ou receptores. }\end{array}$ & $\begin{array}{l}\text { Ampliação das inferências, } \\
\text { conforme proposições. } \\
\text { Identificaçäo de usos, práticas, } \\
\text { tentativas de apropriações. } \\
\text { Disposições discursivas. } \\
\text { Dissipações decorrentes das } \\
\text { defasagens. Novas questōes. }\end{array}$ & $\begin{array}{l}\text { Inferências concétuais sobre } \\
\text { caso em relação com a } \\
\text { ampliaçäo das inferências. O } \\
\text { que o caso aporta de novo para } \\
\text { a compreensão da midiatização, } \\
\text { conforme o contexto reflexivo e } \\
\text { de pesquisa em curso? }\end{array}$ \\
\hline
\end{tabular}

Fig.3. O caso como referência central do método em pesquisa empírica

Mantidos cada um dos três operadores semânticos (abdução, dedução e indução) como inferências de operações relacionadas aos outros dois operadores, cada argumento deixa de ser autônomo em relação ao outro, para ser logicamente solidário e dependente dos outros dois. A inferência dos três níveis (abdução, dedução e indução) é produzida como operação realizada a partir de duas outras proposições-inferências, que comparecem, no argumento, como premissas. Os argumentos são conclusões de outros dois argumentos, permutados na definição do que é dedução, indução e abdução.

Nesse sentido, somente através de uma abstração lógica se podem isolar os argumentos em suas formas simples, relativas aos momentos dedutivo, indutivo e abdutivo, pois, nos processos cognitivos e epistemológicos do espaço acadêmico, os três 
argumentos estão em processos de complexas interpenetrações (em que a matriz acima é apenas um quadro simples, primário). Ou seja, podemos derivar matrizes dessa matriz primária.

\section{Dos modelos à invenção}

Num ambiente interacional hipercomplexo, são possíveis " $\mathrm{n} \times \mathrm{m}^{\text {" casos de }}$ investigação. Ou seja, em decorrência do processo de diferenciação, é possível analisar atores, instituições midiáticas e instituições midiatizadas diversas, em posições variadas nas interações. A análise da circulação demanda recorte nesse complexo de interações: o caso.

O caso é um recorte. Mas qual o método para realizar esse recorte? Certamente, esse método não se determina pela dedução realizada a partir de um modelo abstrato, que define a midiatização como interações entre instituições midiáticas, midiatizadas e atores sociais, derivados dos esquemas de Verón; nem pelo modelo que aborda a midiatização como feixe de relações entre meios/dispositivos, processos de comunicação e processos sociais, decorrentes de nossos esquemas; nem pelo uso de sistemas especialistas (softwares)

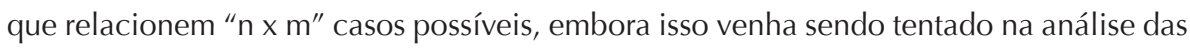
interações em redes digitais e possa servir à construção do caso.

Ou seja, o caso não é uma dedução dos modelos utilizados para a análise da circulação e midiatização até agora construídos. Porém, os modelos têm uma relação simétrica com o objeto observado. Se o que conceituamos de midiatização são as relações entre meios, processos comunicacional-midiáticos e processos sociais, então, quando falamos dessas relações, estamos falando de midiatização; se o que conceituamos de circulação envolve interações entre atores, instituições midiatizadas e instituições midiáticas, então, quando analisamos essas relações, estamos estudando a circulação; se a problemática da circulação é situada na tensão entre contato, contratos, lógicas ternárias e defasagens, quando analisamos a tensão entre esses observáveis, estamos ingressando na problemática da circulação.

Dessa forma, entre modelos mobilizados e observáveis há uma relação circular, não dedutiva, interativa, simétrica (BLACK apud DUTRA, 2006). Porém, como anota essa concepção - da relação metafórica e circular entre modelos mobilizados e observáveis -, há um ponto de fuga, em que o real não está contido na relação circular sugerida, e isso é fundamental na pesquisa sobre a midiatização e circulação, sob pena de sucumbir à autorreferencialidade e ideologia (doxa). Se, como diz Black (1996, p.31 apud DUTRA, 2006, p. 128), "toda a metáfora é a ponta de um modelo submerso", o modelo investigado, mesmo quando modelo de partida, é referencial necessário, mas insuficiente para uma investigação não tautológica. O modelo investigado deve ser desentranhado.

Qual é, então, a função metodológica do modelo referencial? Ele define, em nossa proposição, um ambiente (GOMES, 2011), um cenário, uma paisagem de investigação, em que instituições midiáticas, instituições midiatizadas e atores, meios, processos 
sociocomunicacionais e processos sociais, em que contatos, lógicas e defasagens estão presentes em profusão, borbulhando, com incalculáveis possibilidades de investigação, em torno de um acontecimento (ou caso) midiático, sem resolução estatística possível (pois correspondem a situações indeterminadas e de incerteza).

A análise dessas relações demanda "comparações entre diferentes", o que só pode ser feito por analogias que ultrapassem aquelas identificadas pelos modelos sobre a circulação e midiatização. A primeira delas, sem dúvida, é a metáfora criativa. Aqui, retornamos ao caminho aberto pela proposta de Barthes (1981) (as figuras). As figuras são metáforas com potencial relacional. Elas preenchem os modelos, dão vida aos modelos, os personificam, conforme os casos recortados. É necessário que o pesquisador saia da "mansão desabitada", do mausoléu comunicacional, que é informado pela matriz hipercomplexa, e sinta, em determinado momento, indícios, inferências preliminares, metáforas e potenciais relações metafóricas fortes o suficiente para o instigar à pesquisa. O recorte, nesse sentido, resulta de manchas observadas na matriz hipercomplexa. Uma boa metáfora para esse momento da observação são os fractais:

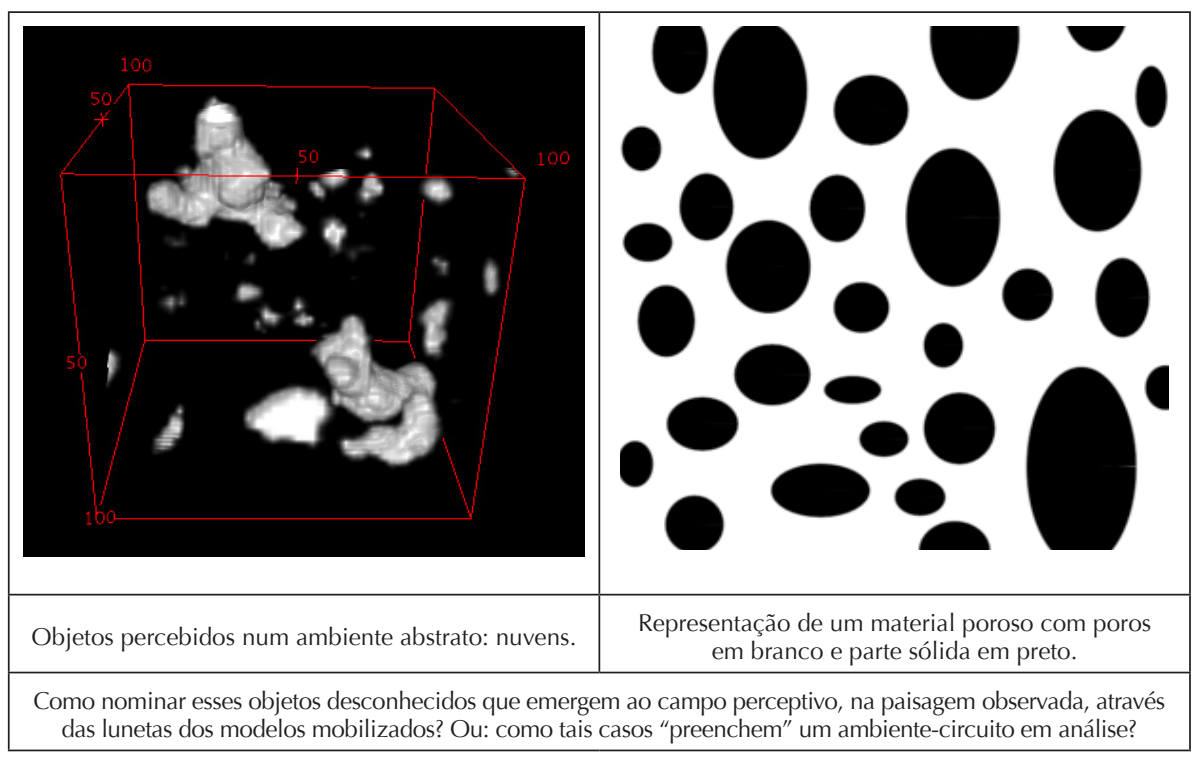

Fig. 4. Representações de fractais

Disponível em: <https://pt.wikipedia.org/wiki/Fractal>. Acesso em: 05.9.2016.

As duas metáforas acima nos ajudam a indicar um caminho argumentativo na construção do caso. Numa imagem de relações abstratas (os modelos sobre a circulação/midiatização e matrizes derivadas, hipercomplexas quando a análise é sobre redes digitais), determinados objetos são percebidos. Produzem percepções 
no investigador (MARCONDES FILHO, 2015), sentimentos, intuições e inferências sobre a paisagem observada. Em termos peirceanos, são indícios que acionam inferências, ícones. Esse passo inferencial é produtor de novas metáforas, que estão além do modelo referencial, que rompem com o circuito tautológico, deslocando o objeto, de um abstrato a um concreto subjetivo. Sugerimos que essa operação analógica é o salto à investigação, na perspectiva da midiatização e circulação. É uma obra do investigador, com reduzido peso das transferências de saber constituído e forte demanda da capacidade inferencial, existencial, energética, emocional e intuitiva do sujeito que pesquisa.

Nesse momento, o pesquisador se defronta com duas referências: uma, aquela derivada dos modelos circulares, recíprocos, que designam um objeto e são designados pelo que se observa; as outras, aquelas derivadas do que se observa na paisagem construída no momento anterior. Uma é lógica; a outra, fluida. Esse embate desigual demanda novas inferências analógicas: como relacionar as metáforas designadas no momento dois? Novo momento criativo do pesquisador, que deve diagramar o que não está dito. Isso lembra Zadig, de Eco. Enfrenta-se a demanda de uma abdução criativa. "A lei precisa ser inventada de novo" (ECO, 2004, p. 229). Enfrenta-se, também, a heterocrítica. Suas figuras inferidas e as relações entre elas devem receber um grau de anuência plausível dos pares que compartilham não só suas referências específicas (manifestas em modelos), mas também as referências concorrentes.

A partir desse ponto, o caso pode ser desenhado como investigação sobre a circulação e midiatização, pois é enriquecido com inferências sobre um real que ultrapassam os modelos referenciais. O caso é um objeto percebido nesse conjunto de relações hipercomplexas, um insight do pesquisador. Esta perspectiva está bem delineada em Ferigolo (2012). A partir de Aristóteles, o autor sugere que a escolha é definida, em parte, pelo pesquisador; em parte, pelo objeto escolhido. Só então as analogias são acionadas, na análise do fenômeno (phainomena), numa perspectiva sempre comparativa entre objetos empíricos, de caso a caso (também comparações analógicas). Feita a escolha, a analogia como operação está condicionada pelo topos, que, nos casos sugeridos, reduz a matriz hipercomplexa a determinados circuitos (BRAGA, 2012) passíveis de análises.

As questões, então, são centrais para que a investigação não se recolha ao conforto, sempre a ser vigiada, tautológica. Há questões específicas e transversais. O caso deve propiciar boas questões específicas. As transversais pertencem à esfera de uma linhagem de pesquisa (midiatização e circulação) e ao campo epistemológico (a comunicação).

Jairo Ferreira é professor titular do Programa de Pós-Graduação em Ciências da Comunicação da UNISINOS. É pós-doutor em comunicação pela UNR (Argentina). Formado em jornalismo e ciências econômicas, 
se tornou mestre em sociologia e doutor em informática na educação, modalidade sanduíche nos Arquivos Jean Piaget e na Unidade de Tecnologias Educacionais da School of Psychology and Education, University of Geneva. Obteve o prêmio Capes-Paped 2001.

jferreira@unisinos.br

\section{Referências}

BARDIN, L. Análise de conteúdo. Lisboa: Edições 70, 2010.

BARTHES, R. Fragmentos de um discurso amoroso. Rio de Janeiro: Livraria Francisco Alves, 1981.

BOUTAUD, J.; VERÓN, E. Sémiotique ouverte: Itinéraires sémiotiques en communication. Paris: Lavoisier, Hermès Science, 2007.

BRAGA, J. L. Circuitos versus campos sociais. In: MATTOS, M. Â.; JANOTTI JUNIOR, J.; JACKS, N. (Org.). Mediação \& Midiatização. Salvador: COMPÓS-EDUFBA, 2012. p. 31-52.

Lógicas da mídia, lógicas da midiatização?. In: FAUSTO NETO, A.; ANSELMINA, N. R.; GINDIN, I. L. (Org.). Relatos de investigaciones sobre mediatizaciones. Rosário, Argentina: UNR, 2015. v. 1, p. 15-32.

DUTRA, L. H. de A. Modelos, analogias e metáforas na investigação científica. Filosofia Unisinos, v. 7, n. 2, p. 126-143, maio/ago. 2006.

ECO, U. Chifres, casos, canelas: Algumas hipóteses acerca de três tipos de abduções. In: O signo de três. São Paulo: Perspectiva, 2004. p. 219-245.

FERIGOLO, J. Conhecimento, dialética, analogia e identidade na biologia de Aristóteles. Tese (Doutorado) - PPG Filosofia, Unisinos, 2012.

FERRARA, L. Os estreitos caminhos do conhecimento. Questões Transversais: revista de epistemologias da comunicação, v. 1, p. 58-65, 2013.

FERREIRA, J. A pólis que se faz em processos midiáticos: proposições sobre a política na perspectiva da midiatização. In: JESUS, E.; TRINDADE, E.; JANOTTI JR, J.; ROXO, M. Reinvenção comunicacional da política: modos de habitar e desabitar o século XXI. Compós.

Campos de significação e conhecimento em dispositivos digitais: análise das interações discursivas em listas de discussão. Tese (Doutorado) - Programa de Pós-Graduação em Informática na Educação - PPGIE-UFRGS, Porto Alegre, 2002.

O caso como referência do método: possibilidade de integração dialética do silogismo para pensar a pesquisa empírica em comunicação. Texto, UFRGS (online), v. 27, p. 161-172, 2012.

Uma abordagem triádica dos dispositivos midiáticos. Líbero, FACASPER, v. 1, p. 1-15, 2006.

FOUQUIER, E. ; VERÓN, E. Les spectacles scientifiques télevisés - Figures de la production et de la réception. Paris: Ministère de la Culture, 1985.

GOMES, P. G. Da sociedade das mídias à midiatização da sociedade. IHU On-Line, UNISINOS (impresso), v. 357, p. 22-24, 2011.

HEPP, A.; HJARVARD, S. Mediatization: theorizing the interplay between media, culture and society. Media Culture Society, v. 37, n. 2, p. 314-324, Março 2015.

LAHIRE, B. Homem plural. Petrópolis: Vozes, 1998. 
MARCONDES FILHO, C. De como a comunicação choca, revela, nos traz de volta ao mundo: sobre o contato com a alteridade dentro e fora das tecnologias comunicacionais. Revista da Associação Nacional dos Programas de Pós-Graduação em Comunicação | E-compós, Brasília, v. 18, n. 1, p. 01-12, jan./abr. 2015.

MIÉGE, B. A sociedade tecida pela comunicação: técnicas de informação e da comunicação entre inovação e enraizamento social. São Paulo: Paulus, 2009.

OLIVERA, G. Eliseo Verón: las condiciones tecnológico-enunciativas de los saberes sobre el sentido o el espesor de la escritura. Estudios, n. 33 p. 109-129, janeiro-junho 2015.

PEIRCE, C. S. Collected Papers of Charles Sanders Peirce. Ed. Charles Hartshorne, Paul Weiss; 19301935; Arthur Burks. Cambridge: Harvard University Press, 1958.

PERAYA, D. Médiation et médiatisation: le campus virtuel. Hermès, La Revue, n. 25, p. 153-167, 1999/3.

PIAGET, J. Biologia e conhecimento: ensaio sobre as relações entre as regulações orgânicas e os processos cognoscitivos. Petrópolis: Vozes, 1973.

PIGNATARI, D. Semiótica e literatura. 6. ed. Cotia: Atelier Perspectiva, 2004.

STRÖMBÄCK, J. Four phases of mediatization: an analysis of the mediatization of politics. The International Journal of Press/Politics, v. 13, n. 3, p. 228-246, Julho 2008.

VERÓN, E. Esquema para el análisis de la mediatización. In: Diálogos de la comunicación, n. 48. Lima: Felafacs, 1997.

Los públicos entre producción y recepción: problemas para una teoría del reconocimiento. Curso da arrábida: Público, Televisão, 2001.

VERÓN, E.; LEVASSEUR, M. Ethnographie de l'exposition: l'espace, le corps et le sens. Paris: Centre Georges Pompidou, 1989.

WALTER-BENSE, E. A teoria geral dos signos. São Paulo: Perspectiva, 2000.

Artigo recebido em agosto de 2015

e aprovado em maio de 2016. 